\title{
Fast-tracking authentic leadership development by means of a programme
}

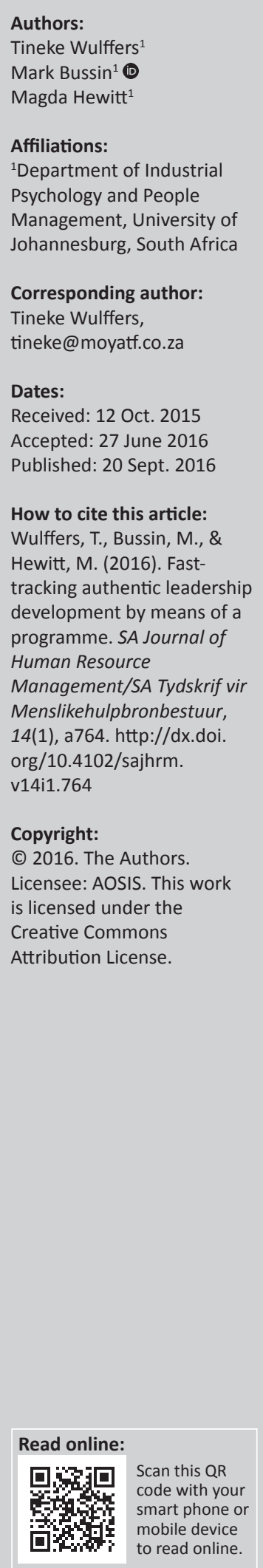

Orientation: While there is considerable literature on the definition and impact of authentic leadership (AL), there is a research gap regarding the effectiveness of AL programmes.

Research purpose: The focus of this article is on the proximal programme effect of an AL development programme on executive leaders within a period of 3 months.

Motivation for the study: AL has been identified not only as the root construct of positive forms of leadership but also equates to the highest level of leadership effectiveness. Leadership authenticity can take a life time to develop, and organisations need positive and ethical leadership now. An appropriate AL programme could considerably shorten the development period of a such leadership

Research design, approach and method: A longitudinal qualitative programme evaluation approach was used. The participants comprised a primary group of a 10-member executive leadership team who were the AL programme participants and their respective secondary (senior, peer and subordinate) participants who provided pre- and post-programme data on the leadership authenticity of the primary participants.

Main findings: The outline of the AL programme is presented with an indication of how it adhered to specific guidelines offered for development of such programmes. Findings indicate that the programme had a proximal effect of increasing AL; starting with the development of personal followed by interpersonal and professional leadership.

Practical/managerial implications: An appropriate and effective AL programme could thus considerably shorten the development period of such leadership.

\section{Introduction}

\section{Key focus}

Good leaders navigate through all weather; profound leadership occurs during a storm. (Meyer, 2007, p. 4)

The above notion illustrates the potential value of authentic leadership (AL), which could be regarded as the highest form of leadership effectiveness (Eigel \& Kuhnert, 2005). To combine high performance with high integrity and to re-instate trust in the free enterprise system requires leaders who know who they are and who produce consistent and predictable leadership behaviour as such leaders foster higher levels of integrity, trust and positive affective responses among followers (Chan, Hannah \& Gardner, 2005; Walumbwa, Avolio, Gardner \& Peterson, 2008). The challenge is that the metric of time required for developing such leadership is typically very long, as it takes life and leadership episodes over time for the characteristics of AL to emerge (Chan, 2005). There is a need for a leadership programme that could possibly fast-track the development of leadership authenticity (Wulffers, 2014).

\section{Background to the study}

The latest rash of corporate scandals over the last decade has awakened collective consciousness to the fact that self-interest, unchecked by moral reasoning and obligation, can result in destructive greed. This greed destroys not only the lives of those executives who are driven by it to ethical compromise but also ultimately impacts on all stakeholders, as the outcomes trickle down the corporate hierarchies, spilling over into communities and crashing into families (Fry \& Whittington, 2005, p. 184).

True leadership is always more difficult to maintain in challenging times, and the unique stressors facing organisations throughout the world today call for a renewed attention to what constitutes 
true and positive leadership (Walumbwa et al., 2008). Organisations are focusing on finding leadership that will restore confidence, hope and optimism, while displaying resiliency that allows appropriate responses to potentially catastrophic events. There is a need for leaders who lead with purpose, values and integrity (George, 2003; Metcalf \& Benn, 2013). What organisations require is a way of leading that is based on character and substance rather than style of leadership and integrity rather than image or position (George \& Sims, 2007).

\section{Trends from research literature}

While there are ample definitions available in literature on AL and how AL impacts on inter-relational trust, individual and team leadership, and organisational effectiveness, there is less information available on how it can be developed. Typically, it takes a long time to develop the characteristics of leadership authenticity, requiring life and leadership episodes that provide development opportunities. This begs the question whether companies can wait that long to have true leaders at the helm (Wulffers, 2014). Unless a way can be found to deliberately develop such leadership within a reasonable time span, organisations and even governments will head the news in stories of corruption and achieving wealth at the expense of their citizens (Karpoff, 2010).

To date, insufficient research has been done on how the development of AL can be fast-tracked (Avolio, 2010; Wulffers, 2014). Avolio and Gardner (2005) highlighted the complexity of AL development theory and stated that they were not yet able to view AL development in the format of a programme, unless it were to be broadly labelled 'life's program' (Avolio \& Gardner, 2005, p. 322), meaning that the development had to emanate from the lessons offered by life.

\section{Research purpose and objectives}

While much has been written about the need for a better quality of leadership (Fry \& Whittington, 2005; George, Sims, Mclean \& Mayer, 2007), very little research is available on how this type of leadership can be developed. Reichard and Avolio (2005) conducted a study on the status of leadership intervention research, pointing out that very little research has been done on AL programmes. They highlighted some high-level aspects that should be present in AL programmes and encouraged researchers to do high-quality research studies on the effectiveness of AL programmes. A subsequent meta-analytic review of leadership impact research by Avolio, Reichard, Hannah, Walumba and Chan (2009) comprised research on 200 leadership interventions from 1950 onwards, and although these authors are regarded as leading researchers in the field of AL, their study did not yet include any AL intervention studies.

Thus, there is a need for further research on the development of leadership authenticity by means of the evaluation of an appropriate programme. This study focused on a practitioner's perspective on developing AL by means of an AL programme. The aim of this article is twofold:

1. To outline the AL programme under study.

2. To report on the evaluation of the impact of this AL programme on the development of leadership authenticity.

\section{Contribution to the field}

AL can be regarded not only as the root construct of positive leadership (Avolio, Gardner, Walumbwa, Luthans \& May, 2004; Avolio, Walumbwa \& Weber, 2009; Gardner, Avolio, Luthans, May \& Walumbwa, 2005) but also meets the requirements for the highest level of leadership (Eigel \& Kuhnert, 2005). However, as the metric of time for developing such leadership authenticity is typically very long (Chan, 2005), it was therefore worthwhile to evaluate an AL programme that not only shortens the development period of such leadership but would also provide organisations with a programme that has been proven to develop AL (Wulffers, 2014).

\section{What will follow}

The next section reviews relevant current literature on $\mathrm{AL}$ and criteria for AL development. The research design is then presented followed by the outline of the programme and the findings from the qualitative research design. The article concludes with the main contributions to the field of an outline and effect of an AL programme on the development on AL, which in itself is an antecedent of leadership effectiveness.

\section{Current knowledge on authentic leadership}

In 2005, the first dedicated monographs on AL theory and practice appeared after the 2004 Nebraska Gallup Leadership Institute summit. In particular, this study is informed by the publication on the emergence, functioning and impacts of veritable AL by Chan et al. (2005), which captured the essence of leadership authenticity. Their AL theory provided the philosophical underpinnings to which the leadership authenticity programme under study is aligned. As this research focused on the development of AL by means of an appropriate programme, the following sections highlight some theoretical perspectives on AL, development of AL and research done on AL programmes.

\section{About leadership authenticity}

The hardest battle which any human being can fight, and never stop fighting in a world which is doing its best, night and day, to make you everybody else, is to be nobody-but-yourself. (Cummings, 1958, p. 1)

The quote by Cummings applies especially in the organisational leadership context, which at times can squeeze the self out of 
oneself (Wulffers, 2014). It is helpful to understand AL by what it is not. AL is not about impression management, which occurs when an inauthentic person acts in deference to external information rather than being aligned to an internal sense of being true to the self (Chan et al., 2005). Impression management might also be the result of a lack of self-awareness of who the self really is, whereas the authentic person will ensure that the impression created is consistent with the true self (Franzese, 2007). Extraordinary leaders are those who are transparent and genuine, therefore commanding respect and admiration, rather than one who is merely posing as a leader, falsely currying favour and trust among followers (Kolditz \& Brazil, 2005).

Increasing self-clarity through self-awareness requires the process of continuous self-reflection or introspection (Akrivou, Bourantas, Mo \& Papalois, 2011; Walumbwa et al., 2008). Introspection and reflection require a dynamic processes that describes the fact that individuals continually question and reassess their values, strengths and weaknesses during leadership episodes that test and further develop leadership authenticity (Freeman \& Auster, 2011; Peus, Wesche, Streicher, Braun \& Frey, 2012). Understanding one's purpose, identity, values, beliefs and psychological states requires not only continuous self-reflection and introspection but also consultation with and feedback from others (George, 2004). Even so, authentic leaders are only human; therefore, they need to display the psychological state of vulnerability in nondefensive recognition of their own weaknesses as well as their strengths (Diddams \& Chang, 2012). This ability, which Leroy and Sels (2008) called balanced vulnerability, in itself becomes a strength allowing for further development. Balanced vulnerability then becomes an internal resource that allows challenging events to trigger heightened self-awareness and self-regulatory behaviours as part of the process of positive self-development (Avolio \& Gardner, 2005; Ladkin \& Taylor, 2010; Weischer, Weibler \& Peterson, 2013).

Positive psychological states (PPS), such as (self-) accountability, (self-) belief, (self-) commitment, (self-) honesty, consistency, courage, truthfulness, respect and trust in self and others, contribute to leadership authenticity. It is the reflection of these aspects in leadership behaviour that will allow the restoration of the public's trust in leadership in the wake of the reported ethical dilemmas (Diddams \& Chang, 2012). Having this understanding of what is morally good and holding oneself accountable for staying aligned with this understanding ultimately leads to psychological ownership (Luthans \& Avolio, 2009), which reflects not only in the leader's behaviour but often also in those of the followers. Leaders who usually reflect relational transparency (Weischer et al., 2013) and balanced processing (Rego, Sousa, Marques \& Pina e Cunha, 2012) develop relationships of trust and mutual respect with their followers. The positive impact of leadership authenticity on the levels of trust, predictability and overall quality of leaderfollower relationships ultimately leads to a positive influence on the development of a culture of authenticity (Clapp-Smith, Vogelgesang \& Avey, 2009; Walumbwa, Luthans, Avey \& Oke, 2011). Therefore, PPS in AL has a direct impact on leadership effectiveness, trust and follower-team effectiveness (Walumbwa et al., 2011).

While AL is a logical extension of the authentic self (Chan et al., 2005), it can also be regarded as the root construct of positive leadership (Avolio \& Gardner, 2005). Therefore, a leader who is authentic can achieve more than one who is not, and the extent to which the leader is authentic as a person directly affects the efficacy of his or her leadership of followers (Chan et al., 2005). In summary, authentic leaders are leaders who know who they are and what they believe in; display transparency and consistency between their values, ethical reasoning and actions; focus on developing positive emotional states such as confidence, optimism, hope and resilience within themselves; and are widely known and respected for their integrity (Avolio, Gardner \& Walumbwa, 2005, p. xxiii).

\section{Development of leadership authenticity}

Referring to increasing leadership development levels, Eigel and Kuhnert (2005) point out that it is important to note that enhancing AL needs to start with mastering personal leadership, before being able to lead others and, ultimately, the organisation as the complexity in leading increases at each level. It is not possible to successfully lead others if selfor personal leadership has not yet been mastered (Barret, 2010). Being able to lead self and others with awareness and authenticity requires a journey of transformation where individuals need to explore the internal identity that drives them and integrate all of life's experiences into a meaningful context (Cashman, 2008; Shamir \& Eilam, 2005).

In order to lead with purpose, which could be regarded as one's highest value (Demartini, 2013), understanding of one's values is required. Therefore, this journey of developing leadership is about getting to know the authentic self and how it needs to be expressed. It is about practising values and principles, understanding what inspired individuals and leading with purpose and passion (George \& Sims, 2007). The following two aspects are important in the development of AL:

- The development of $\mathrm{AL}$ requires exploring what is happening below the 'emotional waterline' or the emotional soil-line. What is meant by this is that behaviour, as noticed by others, therefore visible above the soil-line, is informed by those aspects such as beliefs, values and purpose, which are invisible below the soil-line (Wulffers, 2014).

- New self-awareness does not automatically lead to change. It needs to be supported by new forms of selfregulation (Chan et al., 2005). Existing ways are often habitual, requiring a partnership with an external facilitator or coach to facilitate the change from limiting to empowering habits.

Chan et al. (2005, p. 5) proposed that every leader forms part of a bigger system and that they interact with, influence and receive feedback from other members in their system. They illustrated a process model of the emergence of authentic behaviour, starting 
with self, which proposes six major AL sub-processes: (1) a leader's self-clarity and meta-cognition of the self-system, commonly known as self-awareness; (2) the leader's alignment of self-awareness and self-regulation, that is, aligning the expression of self to the awareness of who the self is; (3) the sense that others (followers) make of the leader's observed behaviour, called perceived leadership authenticity; (4) the resulting true effects this has on followers; (5) the self-verification of the leadership processes through the diagnostic feedback in terms of impact on performance of followers and organisations and finally (6) how this leads to the formation and reinforcement of a more authentic organisational culture. This study focuses mostly on the first two AL sub-processes (self-awareness and aligning self-regulation with self-awareness).

\section{Leadership authenticity programmes}

Although Chan et al. (2005) did not elaborate on the nature of the required leadership programme, they did indicated that the process ought to start with a leadership programme. Reichard and Avolio (2005), in their meta-analysis and summary of the effectiveness of various forms of leadership programmes from 1900 to 2004 concluded that the dominant characteristics of the previous leadership programmes included the use of training manipulations. Moreover, the shift from traditional leadership theories to a focus on a new genre of leadership required a different type of programme. Reichard and Avolio (2005) were not able to include any research on AL programmes, and they encouraged researchers to bridge the practitioner-researcher divide by conducting a greater number of high-quality field programme studies, adding that it is important to adequately test theoretical propositions. They referred specifically to those propositions offered by Cooper, Scandura and Schriesheim (2005), which will be outlined later on. More recent leadership intervention meta-analytic research by Avolio, Reichard et al. (2009) still did not include any data on AL interventions. Recent research by Kinsler (2014) and Gatling (2014) started to explore the link between coaching or coaches and the development of AL, and even so, there seems no evidence of any evaluation of an AL programme yet.

Recommendations for consideration regarding the design of AL programmes were made by several researchers. The AL programme under study adhered to four working assumptions regarding the requirements of effective AL programmes offered by Chan (2005), which builds further on the guidelines of Cooper et al. (2005). These will be further elaborated on during the discussion on findings.

\section{Research design}

This article focuses on the qualitative aspects of a larger mixed-methods programme evaluation study on the effect of an AL programme.

\section{Research approach}

The researcher considered various philosophical research approaches, such as post-positive, social construction, advocacy or participatory and pragmatic (Cresswell, 2009). The selected pragmatist approach can be described as a world-view that arises out of actions, situations and consequences, rather than antecedent conditions. It concerns applications - what works and what does not - and solutions to problems (Creswell, 2009; Teddlie \& Tashakkori, 2004), which is characteristic of programme evaluation.

\section{Research strategy}

The researcher's ontological perspective, in line with postulates outlined by Cresswell (2009), is that there is no such thing as absolute truth and that truth is constructed. This ontology translated into an epistemology of a qualitative approach that allowed for mining of deeper subjective meanings during the participant interviews and data triangulation across various sources of qualitative data. Data triangulation comprised temporal and spatial variation, which was addressed by gathering data from primary and secondary participants. The researcher's practitioner reflective journal was an additional data source for data triangulation to validate and enrich interpretations (Hammersley, 2008).

\section{Research method}

\section{Research setting}

This article focuses on practitioner research. Starting in 2007, the AL programme under study was developed and refined over the years by the researcher who is an AL development practitioner. The practitioner consistently followed an adult experiential learning process as outlined by Kolb and Kolb (2005), where the AL development concrete experiences were followed by reflective observations, which continually yielded new insights that could actively be experimented upon.

The study took place at an international beverage organisation. The researcher was first approached by the Human Resource manager and introduced to the General Manager, who had communicated in writing his belief that '... an intervention is needed to extract the potential from this team and get them to lead the brewery to the performance that is required'. It was agreed that the programme to be evaluated by the researcher was appropriate in terms of the needs of the leadership team.

\section{Entree and establishing researcher roles}

At the outset of the study, a Declaration of Adherence to Ethical Research was signed and submitted to the Ethics Committee of the University of Johannesburg. The sponsor of the participating organisation signed the Research Agreement, and a welcoming letter was sent to all participants. Each participant had to sign a ParticipantInformed Consent form, outlining the research focus, process, benefits and ethical considerations, such as confidentiality and anonymity, to be upheld during the study.

\section{Participants and sampling}

The sample size was not large, which is typical of a leadership team and common in rich qualitative research. The 10-member 
executive leadership team, comprising a natural group, conveniently and purposefully selected, participated in the programme under study and became the primary participants of the programme. The leadership team comprised a general manager, HR business partner, financial manager, brewmaster, brewing manager, packaging manager, engineering manager, operations manager and a systems manager. The primary participants comprised six males and four females, ranging between the ages of 40 and 60 years. Each primary participant selected three secondary participants (their manager, peer and a subordinate), who reported on their experiences of the primary participant before and after the programme. The researcher facilitated the programme and also kept a facilitator's reflective journal. The reason for augmenting participant data with the researcher's data was to address some of the obvious threats to the validity of the data collected, such as social desirability responses, selective memories and interpretation bias (Babbie \& Mouton, 2001).

\section{Data collection methods and instruments}

Once the programme was completed, in-depth qualitative data were gathered from primary participants via semi-structured interviews, to gain a deeper understanding of the effect of the AL programme, as experienced by these participants. Similar data were simultaneously gathered via questionnaires from secondary participants. The researcher, also the facilitator, kept a reflective journal to record her perceptions and experiences of primary participants throughout the programme.

A post-programme semi-structured interview allowed the researcher to extract from each primary participant their narratives, insights and themes of self-reflection of how programme participation had contributed to development of their AL. This interview was piloted to test and refine the questions and establish the time required for the interview. The questions relative to this article that were asked after the intervention were:

- What is your understanding now of leadership authenticity and how does this compare to your previous understanding of leadership?

- How has this leadership authenticity programme contributed to your development as an authentic leader?

- How have specific life or work events helped you both to test and further develop yourself as an authentic leader since starting the programme?

The three secondary participants were requested to answer the following question: 'Since the start of this study, what, if any, changes have you noticed in this leader?'

A facilitator's journal was kept for each participant and was updated with the contents of each session and the facilitator's thoughts and feelings about the content of each session

\section{Recording of the data}

Data collected via semi-structured interviews were, with prior permission from participants, digitally recorded, and all data were safely stored by the researcher.

\section{Data analysis}

Using thematic analysis, the researcher followed the sixphase guide offered by Braun and Clarke (2006, p. 87), supplemented by additional recommendations by various authors on qualitative analysis (Bloomberg \& Volpe, 2012; Saldana, 2009). These included familiarisation with data, generating initial codes, searching for themes, reviewing those themes, defining and naming themes and producing a report. Atlas.ti ${ }^{\circledR}$, a computer-aided qualitative data analysis software programme, was used to assist in administrative processes such as making field notes and creating codes and linking those to data segments, theory building and preparing interim and final reports (Friese, 2012).

As the research was qualitative, the researcher considered the criteria of trustworthiness and credibility during the research. To ensure reliability and validity in the findings, this research followed the guidelines by Lincoln and Guba (1985), ensuring that her findings were credible, transferable, dependable and confirmable (Wulffers, 2014). For instance, she ensured that her findings were trustworthy by allowing data saturation to occur via the semi-structured interview process and by means of triangulating data across various sources. She also conducted member checks with programme participants both on transcribed raw data and interpreted data and kept an audit trail throughout with access to an independent auditor who determined that the study was completed in a dependable manner (Wulffers, 2014).

\section{Reporting style}

The findings are reported theme by theme. Each key finding is supported by at least one direct participant quotation, which includes the participant's identification (P1-P10).

\section{Ethical considerations: Position as practitioner-researcher}

Practitioner research can be defined as research carried out by practitioners for the purpose of advancing their own practice (McLeod, 1999, p. 8), which was the case for this research. The most important factor to guard against bias in such research was practitioner and researcher reflexivity (Cox, 2012; Edmonds \& Candy, 2010), and to such end, the researcher kept a reflective journal of each participant's development, which yielded further practitioner insights after each session. An informed consent form was signed by all research participants, wherein anonymity was ensured.

\section{Findings and discussions}

This research focused on a practitioner's perspective on developing AL by means of an AL programme. An outline of the AL programme under study is presented, followed by the findings of the effect of the AL programme on the development of leadership authenticity. This includes a discussion on leadership episodes that have allowed primary participants to test and further develop their AL during their programme participation. 


\section{Outline of authentic leadership programme}

The conceptual framework of AL development, which underpins the programme under study, is followed by an overview of the six individual AL sessions. These six sessions adhere to the suggestions provided by Eigel and Kuhnert (2005) and Barret (2010) that enhancing AL needs to start with mastering personal leadership, before being able to lead others and, ultimately, the organisation.

In designing the programme, certain decisions were made. The rationale for using a coaching style in facilitating AL programmes is that coaching is about facilitating change through listening, challenging, supporting, questioning, testing and giving feedback (Hall \& Duval, 2002). It is about understanding how we manage our thinking and behaving for more effective performance in life and work. Coaching holds the philosophy that individuals are talented and competent, with many strengths, which aligns with a positive psychology and strengths approach (Kauffman, 2006) to developing leadership authenticity (Gardner, Avolio \& Walumbwa, 2005). In this programme, a coaching style was particularly fitting as it allowed participants to develop a deeper understanding of what AL entailed. It also allowed the participants to develop a deeper self-awareness of their current self-schema, comprising their leadership purpose, vision, legacy, internal identity, values, beliefs about self and others and their psychological states, all invisible below the soil-line, and how these impacted on their behaviour, noticeable to self and others above the soil-line.
The programme started with six individual coaching sessions, approximately 2 weeks apart, which focused specifically on the development of $\mathrm{AL}$, followed by three team sessions 1 month apart, to enhance inter-relational trust and individual and team AL effectiveness. This article focuses on the six individual sessions.

Individual session 1 allowed increased awareness of participants' perceptions of inner and outer landscapes and how these perceptions might work for or against them. Session 2 allowed them to set the intrapersonal, interpersonal and professional leadership outcomes, with accompanying behavioural evidence of successful achievements of those. Assuming that each person is a product of his or her life history, in the third session they explored their life chapters, to obtain a better understanding of various aspects of their self-schemas that culminated into who they currently were. In the fourth session, they used these themes to build a picture of the current self and to determine the strength of the golden thread running across the elements within their self-schema. In session 5, they refined that picture contained in their current self-schema towards a next level of a more congruent possible self, completing the individual journey in session 6 with a review of outcomes achieved thus far.

Figure 1 illustrates the horizontal and vertical aspects of the AL journey that underpinned the six individual sessions. Once participants had identified the leadership outcomes they wished to achieve, the programme helped them to create awareness of selves along a continuous horizontal time-line,

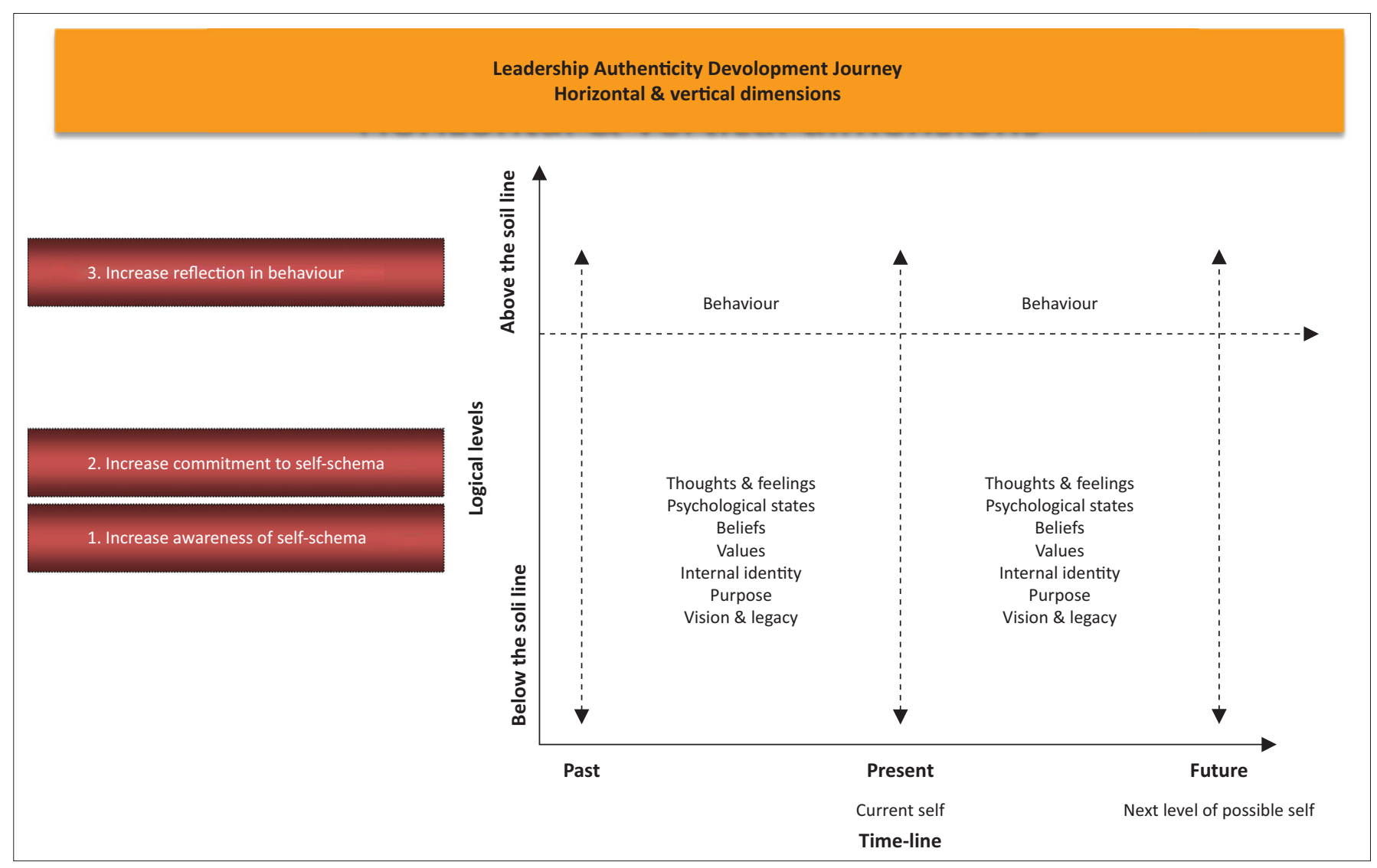

FIGURE 1: Vertical and horizontal aspects of authentic leadership programme journey. 
from their past, through their current, to their future selves. At the same time, they explored along a vertical line aspects below the soil-line that informed their past and current behaviour, which would need to inform their future behaviour and performance. Once that awareness had been created (AL Theme 1), self-regulation could be implemented below the soil-line (AL Theme 2), leading to a more congruent desired self, which could then be reflected in behavioural outcomes above the soil-line (AL Theme 3), in line with the model of AL emergence put forth by Chan et al. (2005).

The evaluated programme adhered to the recommendations by Chan (2005), Reichard and Avolio (2005) and Cooper et al. (2005). Definitive research done by Cooper et al. (2005) suggested four major issues that need to be addressed by any AL development intervention, namely (1) ensuring that the programme itself is authentic, (2) determining how trigger events can be replicated during training, (3) deciding whether ethics-based decision making can be taught and (4) determining who should participate in AL training. The first two considerations were relevant and adhered to in the study reported in this article. The AL programme under study also adhered to four working assumptions regarding the requirements of effective AL programmes offered by Chan (2005), which builds further on the guidelines for AL interventions proposed by Cooper et al. (2005):

- Targeted and customised. Because of the complexity of the $\mathrm{AL}$ construct, there can be no default, one-size-fits-all AL training system.

- High-frequency and micro-interventions. One way to model what authentic leaders go through in real life is to simulate these learning episodes in high-frequency micro-interventions, which would shorten the time required to develop leadership authenticity.

- Self-reinforcing interventions (over time). AL interventions need to be self-reinforcing, so as to sustain development over time.

- Multilevel, nested interventions. Leaders never operate in isolation, and while the context(s) in which the leader operates impacts on the leader, the leader also needs to acknowledge that he or she is able to be an agent of change.

The individual sessions typically run over $2-3$ months and adhere to all the afore-mentioned criteria.

\section{Effect of the authentic leadership programme on the development of leadership authenticity}

The majority of participants indicated that the programme had had a noticeable effect on the development of their leadership authenticity. These effects are elaborated on in the following findings from the qualitative data from the postprogramme semi-structured interviews and questionnaires and from the facilitator's journal. The discussion of the findings is grouped, wherever possible, into the following categories: development of personal, interpersonal and organisational AL in the work context, and within those, the following three AL themes - AL1: awareness of self-schema,
AL2: commitment to that awareness (self-regulation) and AL3: behavioural reflection of that self-regulation.

\section{Programme effect on personal authentic leadership}

AL1: Awareness of self-schema: Authentic leading starts with being able to lead oneself, before one can lead others. The findings indicated that the programme led to a noticeable increase of both the participants' understanding of and development in AL.

Reflections on their self-awareness before the programme: Before commencement of the programme, there was limited awareness of the notion of AL, illustrated by the following quote:

P10: 'I don't know if I had an understanding of what leadership authenticity was before.'

In line with findings by Kolditz and Brazil (2005), participants sensed that most leadership styles did not acknowledge the authentic self, rather prescribing a one-fit-for-all skill set that was transactional in nature pertaining to organisational outcomes only:

P 6: '... like, you know, your 10-day MBA. They'll put in ... some extracts about what good leadership is. ... I think it was very prescriptive; it always comes with a formula ... it always put up an ideal identity that you need to live up to.'

Before the programme, participants experienced mostly a lack of self-awareness or self-knowledge of their own selfschemas. Not only did they not realise how they contributed to the problems within their team, they also did not realise their potential:

P10: 'I don't think I was optimistic or overestimated it was just where I was not knowing what my potential could be in a sense. Knowing that there's probably a lot more growth that I could get out of me ... I think I didn't know what I didn't know in a sense, I didn't know what I could still grow at.'

Reflection on their self-awareness after the programme: During the programme, they started the process of continuous introspection towards increasing self-awareness:

P 8: 'I think it's had a huge change on me. It gave me the opportunity to get to know myself a lot better. It gave me the time to actually become comfortable with myself, understand myself, understand the values that I have, being able, I suppose, to some extent articulate that and be comfortable to articulate that ....'

This example is in line with suggestions by Akrivou et al. (2011) and Peus et al. (2012) about the importance of selfawareness gained through introspection. Similar to thoughts by George (2004) regarding underpinnings of authentic behaviour, participants referred specifically to aspects that drive behaviour, such as core beliefs, core values, internal identity and purpose or vision or legacy. This quote illustrates these underpinnings:

P 7: 'I've learnt to see the value in what I really want out of life. Purpose in terms of, it talks to the vision, so that's changed a lot for me. Identity has changed in terms of me being more authentic and true to myself ....' 
The increased self-awareness also pertained to what they believed about self, others and even what leadership really could entail, as the following quotation illustrates. As a result, their self-knowledge about their potential became clearer and resulted in increased self-confidence, requirements for AL as postulated by Diddams and Chang (2012):

P 4: 'So what it's done is, it's giving me a lot more scope to understand the people not just myself. So understanding yourself, part of that learning to understand yourself better, is to understand everybody else better ... Work is around relationships. At the end of the day everybody works and lives in a world where relationships are important.'

A programme such as this can never be evaluated in isolation. Aligned with Cooper et al. (2005) and Freeman and Auster (2011), it needs to be cognisant of and use trigger events to test and further develop leadership authenticity. Participants were able to identify specific work episodes that had tested and further developed their awareness of self and others towards increased leadership authenticity, leading to more trusting relationships, for example:

P 9: 'I think through the programme what I learnt is that he would rather listen to stuff through his ear than actually read them in an email or a message whatever. So that's one thing. I try to keep him a little bit more informed verbally, even if it's just try touch by his office or whatever.'

These key findings illustrate that the programme had a noticeable effect on increased understanding of $\mathrm{AL}$ and increased self-awareness of the self-schema.

AL2: Commitment to self-schema (self-regulation): Participants' reflections on their commitment to their selfschema (self-regulation) before the programme: Participants understood that before the programme they were simply deluding themselves and that they were lacking in positive psychological states, as the following illustrates:

P 1: 'not dealing with it and thinking you're okay. So if I ignore this thing, I'll just live with it. I'll just file it at the back of my mind but oh, I'm okay. I think I was fooling myself ... I think it's about not wanting to deal with it ... So it's about - again, we spoke about it earlier - the self-belief, the gut feel, the giving more to other people than to myself, not wanting to face conflict ...'

Reflection on their commitment to their self-schema (selfregulation) after the programme: In terms of commitment to being true to one's self and one's core values, once an awareness of the drivers of the participant's behaviour was in place, self-regulation could follow. As illustrated in Table 1, increased awareness lead to increased internal management of positive psychological states such as accountability (psychological ownership), appropriate vulnerability, commitment, consistency, self-belief, selfconfidence, self-discipline, self-honesty, truthfulness and trust.

Accountability (self-ownership), commitment, consistency, self-belief, self-confidence, self-discipline, self-honesty, truthfulness and trust are all requirements of $\mathrm{AL}$ as highlighted by Avolio and Gardner (2005) and Walumbwa et al. (2008). Regarding appropriate vulnerability, also referred to by Leroy and Sels (2008) as balanced vulnerability, the programme helped participants to develop appropriate strength-based vulnerability so that they could accept and grow from feedback from others, which further led to the development of intrapersonal and interpersonal trust, which supports the postulates by Diddams and Chang (2012). Increased self-belief, self-confidence, self-discipline, self-honesty and being true to self, in line with postulates by Avolio et al. (2005) and Walumbwa et al. (2008) resulted in participants who previously wished to leave the organisation to develop more hope in their current situation.

These findings illustrate that the programme had a noticeable effect on increased commitment towards a more authentic self-schema within primary participants.

TABLE 1: Examples of development of positive psychological states.

\begin{tabular}{|c|c|}
\hline Positive psychological states & Example of response \\
\hline Accountability & $\begin{array}{l}\text { P6: 'So you generally just used to find yourself upset and angry and not getting results but I've learnt, for example, I can now sit } \\
\text { and assess - instead of getting angry about that person's response, I must just accept they responded that way. They can own } \\
\text { that response; it's not mine to own. So there are little tools that help you deal with stuff on a day-to-day basis.' }\end{array}$ \\
\hline Appropriate (balanced) vulnerability and trust & $\begin{array}{l}\text { P6: 'I think I have shifted in the way I approach the team, for example. The trust has improved; I've opened up a little bit more. } \\
\text { Like I said, I've found common ground between me and some people. The programme also forced me to do some things that I } \\
\text { really was not planning to do. Like? Get feedback from other people; consider the feedback from other people.' }\end{array}$ \\
\hline Commitment and consistency & $\begin{array}{l}\text { P9: 'I think I've learnt a lot in terms of leadership. And it's not just about the situational leadership that I spoke about, it's about } \\
\text { the commitment levels, it's about the values that we learnt about, and it's about understanding, it's about forgiveness in many } \\
\text { instances, it's about making mistakes but learning from them, it's about being seen - irrespective of the circumstance - being } \\
\text { seen consistent in terms of your core values.' }\end{array}$ \\
\hline Self-belief & $\begin{array}{l}\text { P10: 'I think that aspect - that whole self-belief aspect, has grown immensely in terms of my value to, whether it's to my family, } \\
\text { or to my organisation, even just to the brewery, that has grown.' }\end{array}$ \\
\hline Self-confidence & $\begin{array}{l}\text { P1: 'So up with the confidence levels, realising that I've got some very good things to offer and work on the things that I am not } \\
\text { so good at.' }\end{array}$ \\
\hline Self-discipline and consistency & $\begin{array}{l}\text { P1: '... the most important is self-discipline ... I was lacking in a big way, a big way on that one. So it's self-discipline; not to } \\
\text { procrastinate. Now what this programme has taught me ..., it taught me the impact or the value of doing the things that you } \\
\text { sometimes think are not going to add value for you and how much value it actually did add. So it was the self-discipline, not } \\
\text { procrastinating, the big thing, the consistency, and the biggest of all my self-belief - that was the biggest thing.' }\end{array}$ \\
\hline Self-honesty & $\begin{array}{l}\text { P1: 'Yes, self-honesty. And again, I said it right in the beginning, it's knowing yourself. Sometimes you don't like it and you just file } \\
\text { it in the back of your mind and you think it's going to go away, it's not. This teaches you - this programme draws these things out } \\
\text { of you, that's what it does.' }\end{array}$ \\
\hline True to self and consistency & $\begin{array}{l}\text { P2: '... being more true to myself means that I'm more consistent. So if what you do has got a negative consequence but you can } \\
\text { reflect back on it and say [that] my motivation, or my reasons, or my actions, or whatever were pure and aligned to what I } \\
\text { believe in, then you can feel comfortable with those actions.' }\end{array}$ \\
\hline
\end{tabular}


AL3: Behavioural reflection of self-regulation in participants' behaviour: Reflecting self-regulation in behaviour before the programme: The lack of self-regulation in participants before the programme manifested in, among others, not dealing with issues, and at times, taking inappropriate responsibility for others, as illustrated from the researcher as facilitator's reflective journal:

Facilitator's reflection: 'I asked P9 how happy he was at work at the moment, and he admitted that he was frustrated and unhappy ... He also was starting to ask how he was adding to the problem, and what he needed to do to be part of the solution ... This was creating a tension in him at the moment ...'

Reflecting self-regulation in behaviour after the programme: Secondary participants noticed that primary participants were more willing to do continuous introspection, resulting in increased psychological state management, reflected in their behaviour. In particular, they noticed increased consistency, relational transparency, confidence and balanced processing, illustrated by the examples in Table 2 . Rego et al. (2012) and Weischer et al. (2013) suggest that qualities such as consistency, relational transparency, confidence and balanced processing are AL qualities that further lead to developing relationships of trust and mutual respect with their followers.

Participants gave examples of leadership episodes where they had been tested in terms of changes in their behaviour, such as the positive impact of being able to conduct crucial conversations and relationship building that led to better team delivery. They were also better able to hold team members accountable for delivery, and even on occasion, hold their seniors accountable for their behaviour, as illustrated in Table 3.

Authors on AL, such as Chan et al. (2005) and Peterson, Walumbwa, Avolio and Hannah (2012), often refer to the impact of AL on followers without necessarily limiting those to sub-ordinates. These findings indicate that authentic leaders could even, at times, lead those senior to them, illustrating that they lead by presence rather than position.
These key findings illustrate that the programme had a noticeable effect on increased reflection of self-regulation in the behaviour of participants. Furthermore, there was an indication of an increase in all three AL sub-processes, as outlined by Chan et al. (2005), resulting in a noticeable increase in personal AL.

\section{Programme effect on interpersonal authentic leadership}

The findings indicated the programme had a noticeable effect on both the understanding and development of interpersonal AL. Whereas all three AL themes were required in developing personal $\mathrm{AL}$, only the third was required in developing interpersonal AL.

AL3: Reflection of self-regulation in participants' behaviour: Reflection of self-regulation in participants' behaviour before the programme: In terms of the participants' original perspectives on interpersonal AL, participants had previously been introduced to the notion of engaging leadership. However, there was a sense that, even if leaders are encouraged to engage with others, they were not necessarily authentically doing so; rather than showing their true selves, they would create an impression that they were truly engaging with others, as the following quotation illustrates. Avolio and Gardner (2005), Chan et al. (2005), Franzese (2007) and Walumbwa et al. (2008) call this impression management, which does not constitute AL:

P 7: 'But general leadership, I was always believed that it was something where you had to put on a facade and behave a certain way and not show your true self.'

Reflection of self-regulation in participants' behaviour after the programme: During the programme, one participant realised that appropriate vulnerability, also called balanced vulnerability, allowed him to be open to others:

P 5: 'Taking people into your confidence, I suppose that's part of openness really. (Interviewer) Appropriate vulnerability? I'm just checking. P 5: Yes, you are exactly right.'

Participants realised the importance of consistently holding others accountable, as others would then know what the

TABLE 2: Examples of positive psychological states as noted by secondary participants.

\begin{tabular}{|c|c|}
\hline Positive psychological states & Example of response \\
\hline Introspection & $\begin{array}{l}\text { P7: (senior) 'I have noticed her willingness to understand herself better and to work on her gaps. She can see the benefit and } \\
\text { wants to create that ideal individual leader as well as that ideal team player. She worked hard at it.' }\end{array}$ \\
\hline Consistency & P2: (peer) 'Specifically how she keeps her behaviour consistent when faced with challenges.' \\
\hline Relational transparency & P2: (subordinate) 'P2 is more transparent in her approach.' \\
\hline Confidence & $\begin{array}{l}\text { P2: (senior) 'She is more comfortable with who she is. She has grown in confidence in her own abilities. She speaks with more } \\
\text { confidence. She carries herself with more confidence.' }\end{array}$ \\
\hline Balanced processing & $\begin{array}{l}\text { P8: (subordinate) 'He has also calmed down and is willing to debate and rational around issues that are going wrong. He is more } \\
\text { consistent in his approach and is open to engage in difficult discussions.' }\end{array}$ \\
\hline
\end{tabular}

TABLE 3: Examples of leadership episodes that tested or further developed authentic leadership.

\section{Leadership episodes}

Impact on crucial conversations

Impact on holding others accountable

Impact on better delivery

\section{Example of response}

P7: '... I've given feedback to P8 in our sessions where I've seen him change a lot. At the same time I've actually given him feedback saying, "P8, don't change too much because you're going to lose yourself in the process".... Sometimes he tries very hard and I was able to give him on-the-level feedback. I'm also able to give him feedback about where I believe peers can improve, at the same giving the peers feedback themselves.'

P1: 'I let go but when I let go, I put in place accountability.'

P4: 'I think that's important, is that it's not just about you, another individual could have something that's important to them and you can't discount it. If it's important to them you need to take it seriously, have the discussion but ultimately it is important to them so deliver on it.' 
leader expected of them and the importance of meaningful and empowering communication:

P 1 on holding others accountable: 'They've got to know that is exactly what P1 wants, that I know he's going to react that way, I know he's going to hold me accountable and that's that.'

P 6 on meaningful and empowering communication: '... true to me - know what's true to me as a person, know what drives me, understand how I see the world, understand how I see other people. I think once I understood that it became easier to interact with others around me in a much more real and meaningful way. So for me it's really about understanding myself within the context of the world to be able to live up to the best vision of who I want to be.'

They referred to understanding and adhering to increased positive psychological states of interpersonal respect and interpersonal trust and realised the importance of truly knowing themselves. This reflected in their behaviour as it allowed them to engage in meaningful and empowering communication with others, which concurs with findings by Archer (2009), as illustrated in Table 4.

However one participant was less optimistic and referred to the fact that he himself remained part of the problem, indicating that each participant was not yet at the same leadership development level, in line with findings by Eigel and Kuhnert (2005):

P 5: 'No, that was the big thing for me. I think downwards I've been strong in the past and I think my style is reasonably consistent with the model. Upwards I've been particularly weak. I haven't managed to fix that.'

In line with claims by Rego et al. (2012), secondary participants noticed significant changes in terms of increased balanced processing. For instance, one participant had become more open and engaging and no longer strictly results-driven and only interested in the bottom line. She had also toned down her directive leadership style. There had also been a move towards more balanced processing in the leader of the team; instead of autocratic style of leadership, he became more willing to listen, as the following illustrate:

P 7: (peer) 'I think the feedback that she had has made her tone down her over direct way of approaching people.'

P 8: (subordinate) 'P8 has changed considerably - he no longer dictates what needs to be done instead he listens to opinions and lets the team formulate a way forward.'

These findings illustrate that the programme had a noticeable effect on increased reflection of interpersonal self-regulation in the behaviour of participants, as noticed both by primary and secondary participants. This is in line with the third AL sub- process outlined by Chan et al. (2005), resulting in a noticeable increase in interpersonal AL within the participants.

\section{Programme effect on organisational authentic leadership}

In terms of their original perspectives on the notion of organisational leadership, participants considered this to be restricted mainly to positional leadership and being taskfocused and driving results, illustrated as follows:

P 5 on positional leadership: 'Before I just worked on downward leadership, I didn't really think of working on upward or peer leadership.'

P 8 on being mainly task-focused: 'It was about the hard numbers and I suppose it still is about the hard numbers. I suppose in retrospect, if I'd changed my approach I might've been able to turn it quicker by not just focussing on the task or maybe give a little bit more of a balanced approach to it.'

Concurring with postulates by Avolio et al. (2005), during the programme participants realised that leadership authenticity forms the root construct of positive leadership:

P 7: 'It would make it [engaging leadership] more effective if the person was true to themselves in their day-to-day activities. Being true to yourself and actually being genuine - ... Because you can see through people that are putting on a façade because their behaviours change daily; whereas somebody that's genuine and no matter what day or what time you approach them, you almost know what their response is going to be ...'

Similar to suggestions by George and Sims (2007), it is a type of leadership that went beyond position and a balanced situational leadership that allowed one to be true to oneself both in and beyond the organisational environment. This, in turn, allowed the leader to create a culture worth following, which was conducive to the achievement of results, as postulated by Chan et al. (2005) and Walumbwa et al. (2011), as the following response indicates:

P 3: 'It's how true you are to both yourself and to the environment or the people that you're working with ... So it does talk to both your internal values and I think we relate - the company has got values and they publish these values. I wouldn't be able to work in a company where I couldn't subscribe to those values and I think that's part of it ... That's what it is. It's being true to that.'

Secondary participants noticed how developing leadership authenticity in primary participants had enhanced effectiveness and commitment within the team, in line with findings by Clapp-Smith et al. (2009). Primary participants had also developed a more empowering style of leadership, which also confirms findings by Walumbwa et al. (2011):

P 7: (subordinate) 'She has become more open and engaging and not strictly results-driven and only interested in the bottom-line.'

TABLE 4: Examples of positive psychological states.

\begin{tabular}{ll}
\hline Positive psychological states & Example of response \\
\hline Interpersonal respect & P1: 'In general, there seemed to be more respect for other people's opinions.' \\
Interpersonal trust & $\begin{array}{l}\text { P6: '... One would assume that it's obvious but it just }- \text { I don't know what it was that was stopping me or anybody else for that } \\
\text { matter. So it shifted me in terms of engaging with people, being more open, the trust I think has improved quite a lot.' }\end{array}$ \\
$\begin{array}{l}\text { Meaningful empowering communication } \\
\text { Fith him. When she just gave him feedback on why she did not react more about the P6 incident, he visibly relaxed. He told her } \\
\text { that he was learning from her ....' }\end{array}$ \\
\hline
\end{tabular}


These findings illustrate that the programme had a noticeable effect on increased understanding of $\mathrm{AL}$ and an increased reflection self-regulation in the behaviour of participants, as noticed by the primary and their secondary participants. This is in line with the third AL sub-process outlined by Chan et al. (2005), resulting in a noticeable increase in organisational AL within the participants.

\section{Conclusion, limitations and implications for practice}

Findings indicated that the programme had a proximal impact on the enhancement of personal, interpersonal and professional AL leadership. Figure 2 illustrates, at a metalevel, the programme effect on AL development.

From the personal perspective, it became clear that the enhancement of personal AL required all three AL subprocesses, namely (1) developing more self-awareness regarding the elements of purpose, identity, values and beliefs within the self-schema, (2) self-regulation to better align these elements and (3) reflecting this self-regulation in behaviour.

From an interpersonal perspective, once personal AL had been developed, interpersonal AL required mainly the third AL sub-process, which was to reflect, through selfregulation, a true self in behaviour that followers could notice. Relational transparency and consistency in behaviour became noticeable and participants became much more relational orientated.

From an organisational leadership perspective, participants realised after the programme that AL forms the root construct of positive leadership. It is a leadership by presence that goes beyond position and allows one to be true to self, while also being true to one's organisational environment. This further allows one to create a culture that others wish to be part of and in which results can be achieved.

\section{Potential limitations and recommendations for further research}

The main limitations of this study were that there was only one leadership team that comprised the programme participant sample; therefore, the findings of this study cannot be generalised. Although the individual sessions in this empirical study ran over 3 months and data were collected after the programme, indicating that changes had been made towards increased $\mathrm{AL}$, the question remained whether these changes could be sustained. This study opens a new area of possibilities for further research, as follows:

- With additional leadership teams as programme participants.

- The impact of enhancement of AL on organisational outcomes.

- Further longitudinal research on the sustainability of AL growth gained from participating in an AL programme.

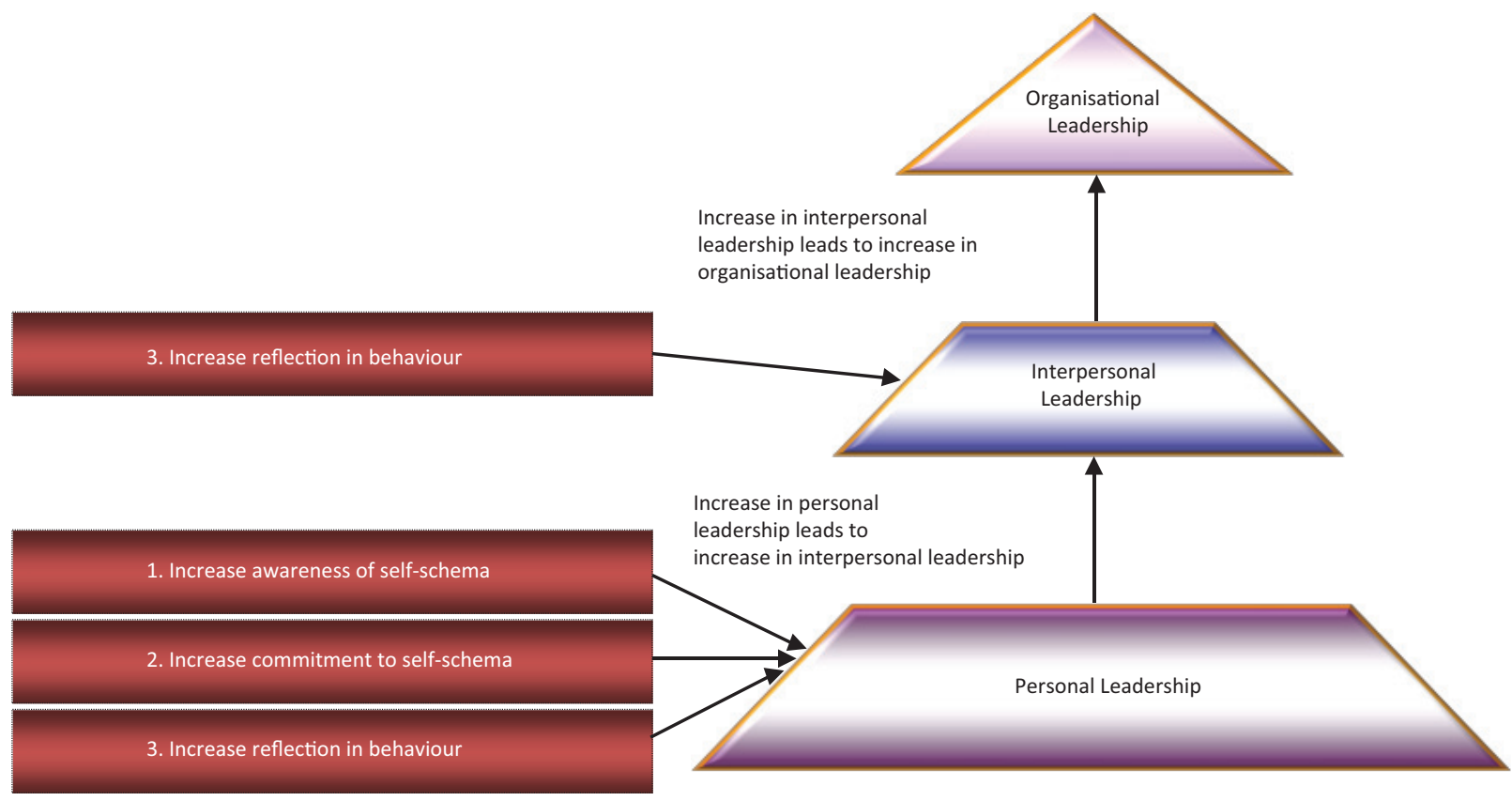

FIGURE 2: Programme impact on development of authentic leadership. 


\section{Main contribution}

For some in leadership positions, it can take years, even a life time, to discover the true self at a deep and meaningful level. It can take even longer to master the regulation of the various processes below the soil-line that allows the leader to sustain authenticity; not only within but also in the leadership role and purpose to which he or she needs to be true. Whereas most research on leadership authenticity focuses on what it entails, how it impacts and considerations in the development of such leadership, the uniqueness of this research is that it focused from an empirical perspective on the proximal programme effect on development of AL. It determined that the AL programme adhered to guidelines for such programmes and had a noticeable proximal effect on enhancing leadership authenticity within a period of 3 months.

\section{Acknowledgements Competing interests}

The authors declare that they have no financial or personal relationships which may have inappropriately influenced them in writing this article.

\section{Authors' contributions}

T.W. was responsible for experimental and project design and performed the research and wrote the article. M.B. and M.H. made conceptual contributions and supervised the research.

\section{References}

Akrivou, K., Bourantas, D., Mo, S., \& Papalois, E. (2011). The sound of silence - A space for morality? The role of solitude for ethical decision making. Journal of Business Ethics, 102, 119-133. http://dx.doi.org/10.1007/s10551-011-0803-3

Archer, M.A. (2009). Authentic teaming: Undiscussables, leadership and the role of the consultant. Organization Development Journal, 27(4), 83-92.

Avolio, B.J. (2010). Pursuing authentic leadership development. In N. Nohria \& R Khurana (Eds.), Handbook of leadership theory and practice (pp. 721-750). Boston, MA: Harvard Business Press Books.

Avolio, B.J., \& Gardner, W.L. (2005). Authentic leadership development: Getting to the root of positive forms of leadership. The Leadership Quarterly, 16(3), 315-337.

Avolio, B.J., Gardner, W.L., \& Walumbwa, F.O. (2005). Preface. In W.L. Gardner, B.J. Avolio, \& F.O. Walumbwa (Eds.), Monographs in leadership and management volume 3: Authentic leadership theory and practice: Origins, effects and development (pp. xxi-xxix). Amsterdam: Elsevier.

Avolio, B.J., Gardner, W.L., Walumbwa, F.O., Luthans, F., \& May, D.R. (2004). Unlocking the mask: A look at the process by which authentic leaders impact followe attitudes and behaviors. The Leadership Quarterly, 15(15), 801-823. http:// dx.doi.org/10.1016/j.leaqua.2004.09.003

Avolio, B.J., Reichard, R.J., Hannah, S.T., Walumba, F.O., \& Chan, A. (2009). A metaanalytic review of leadership impact research: Experimental and quasiexperimental studies. The Leadership Quarterly, 20, 764-784. http://dx.doi. org/10.1016/j.IsU.2009.06.006

Avolio, B.J., Walumbwa, F.O., \& Weber, T.J. (2009). Leadership: Current theories, research and future directions. Annual Review of Psychology, 60, 421-449. http:// dx.doi.org/10.1146/annurev.psych.60.110707.163621

Babbie, E., \& Mouton, J. (2001). The practice of social research. Cape Town: Oxford University Press Southern Africa (Pty) Ltd

Barret, R. (2010). The new leadership paradigm. Richard Barret.

Bloomberg, L.D., \& Volpe, M. (2012). Completing your qualitative dissertation: A roadmap from beginning to end. California, MD: Sage Publications.

Braun, V., \& Clarke, V. (2006). Using thematic analysis in psychology. Qualitative Research in Psychology, 2006(3), 77-101. http://dx.doi.org/10.1191/1478088706qp063oa

Cashman, K. (2008). Leadership from the inside out. Becoming a leader for life. San Francisco, CA: Berret-Koehler Publishers, Inc.

Chan, A. (2005). Authentic leadership measurement and development: Challenges and suggestions. In W.L. Gardner, B.J. Avolio, \& F.O. Walumbwa (Eds.), Monographs in leadership and management volume 3: Authentic leadership theory and practice: Origins, effects and development (pp. 227-250). Amsterdam: Elsevier.
Chan, A., Hannah, S.T., \& Gardner, W.L. (2005). Veritable authentic leadership: Emergence, functioning and impacts. In W.L. Gardner, B.J. Avolio, \& F.O. Walumbwa (Eds.), Monographs in leadership and management volume 3: Authentic leadership theory and practice: Origins, effects and development (pp. 3-41). leadership theory and

Clapp-Smith, R., Vogelgesang, G. R., \& Avey, J. B. (2009). Authentic leadership and positive psychological capital: The mediating role of trust at the group level of analysis. Journal of Leadership \& Organizational Studies, 15(3), group level $227-240$.

Cooper, C., Scandura, T., \& Schriesheim, C. (2005). Looking forward but learning from our past: Potential challenges to developing authentic leadership theory and our past: Potential challenges to developing authentic leadership theory and
authentic leaders. The Leadership Quarterly, 16(3), 475-494. http://dx.doi. authentic leaders. The Leadership
org/10.1016/j.leaqua.2005.03.008

Cox, R. (2012). Teaching qualitative research to practitioner-researchers. Theory into Practice, 51, 129-136. http://dx.doi.org/10.1080/00405841.2012.662868

Cresswell, J.W. (2009). Research design: Quantitative, qualitative and mixed methods approaches. California, MD: Sage Publications.

Cummings, E.E. (1958). A poet's advice. Retrieved August 08, 2012, from http://www. thepositivemind.com/poetry/APoet\%27sAdvicepoem.html

Demartini, J. (2013). The values factor. New York: Penguin Group.

Diddams, M., \& Chang, G.C. (2012). Only human. Exploring the nature of weakness in authentic leadership. The Leadership Quarterly, 23, 593-603. http://dx.doi. org/10.1016/j.leaqua.2011.12.010

Edmonds, E., \& Candy, L. (2010). Relating theory, practice and evaluation in practitioner research. Leonardo, 43(5), 470-476.

Eigel, K.M., \& Kuhnert, K.W. (2005). Authentic development: Leadership development level and executive effectiveness. In W.L. Gardner, B.J. Avolio, \& F.O. Walumbwa (Eds.), Monographs in leadership and management volume 3: Authentic leadership theory and practice: Origins, effects and development, (pp. 357-386). Amsterdam: Elsevier.

Franzese, A.T. (2007). To thine own self be true? An exploration in authenticity Doctorate of Philosophy in the Department of Sociology, Graduate School of Duke University, New York.

Freeman, R., \& Auster, E.R. (2011). Values, authenticity, and responsible leadership. Journal of Business Ethics, 98, 15-23. http://dx.doi.org/10.1007/s10551-0111022-7

Friese, S. (2012). Qualitative data analysis with ATLAS.ti. London: Sage Publications, Ltd.

Fry, L.W., \& Whittington, J.L. (2005). In search of authenticity: Spiritual leadership theory as a source for future theory, research, and practice on authentic leadership. In W.L. Gardner, B.J. Avolio, \& F.O. Walumbwa (Eds.), Monographs in leadership and management volume 3: Authentic leadership theory and practice: Origins, effects and development (pp. 183-202). Amsterdam: Elsevier.

Gardner, W.L., Avolio, B.J., Luthans, F., May, D.R., \& Walumbwa, F.O. (2005). 'Can you see the real me?' A self-based model of authentic leader and followe development. The Leadership Quarterly, 16(16), 343-372. http://dx.doi. org/10.1016/j.leaqua.2005.03.003

Gardner, W.L., Avolio, B.J., \& Walumbwa, F.O. (2005). Authentic leadership development: Emergent themes and future directions. In W.L. Gardner, B.J. Avolio, \& F.O. Walumbwa (Eds.), Monographs in leadership and management volume 3 : Authentic leadership theory and practice: Origins, effects and development (pp. 357-386). Amsterdam: Elsevier.

Gatling, A. (2014). The authentic leadership qualities of business coaches and its impact on coaching performance. International Journal of Evidence Based Coaching and Mentoring, 12(1), 27-46.

George, B. (2003). Authentic leadership: Rediscover the secrets to creating lasting value. San Francisco, CA: Jossey-Bass.

George, B. (2004). The journey to authenticity. Retrieved September 09, 2014, from http://www.hbs.edu/faculty/Pages/item.aspx?num $=16233$

George, B., \& Sims, P. (2007). True north: Discover your authentic leadership. San Francisco, CA: Jossey-Bass.

George, B., Sims, P., Mclean, A.N., \& Mayer, D. (2007). Discovering your authentic leadership. Harvard Business Review, 85, 129-130, 132-138, 157.

Hall, L.M., \& Duval, M. (2002). Meta-coach training system and certification. Clifton, VA: Neuro-Semantic Publications.

Hammersley, M. (2008). Troubles with triangulation. In M.M. Bergman (Ed.), Advances in mixed methods research (pp. 1-8). London: Sage Publications Ltd.

Karpoff, J. (2010). The decade's worst financial scandals. Retrieved n.d., from http:// foster.uw.edu/research-brief/the-decades-worst-financial-scandals/

Kauffman, C. (2006). Positive psychology: The science at the heart of coaching. In D.R. Stober \& A.M. Grant (Eds.), Evidence based coaching handbook (pp. 219-254). Hoboken, NJ: John Wiley \& Sons, Inc.

Kinsler, L. (2014). Born to be me ... whom am I again? The development of authentic leadership using evidence-based leadership coaching and mindfulness. International Coaching Psychology Review, 9(1), 92-105.

Kolb, A.Y., \& Kolb, D.A. (2005). The Kolb learning style inventory - Version 3.12005 technical specifications. Cleveland, $\mathrm{OH}$ : Cape Western Reserve University.

Kolditz, T.A., \& Brazil, D.M. (2005). Authentic leadership in extremis settings: A concept for extraordinary leaders in exceptional situations. In W.L. Gardner, B.J. Avolio, \& F.O. Walumbwa (Eds.), Monographs in leadership and management Avolio, \& F.O. Walumbwa (Eds.), Monographs in leadership and management
volume 3: Authentic leadership theory and practice: Origins, effects and development (pp. 345-356). Amsterdam: Elsevier. 
Ladkin, D., \& Taylor, S.S. (2010). Enacting the 'true self': Towards a theory of embodied authentic leadership. Leadership Quarterly, 21(1), 64-74. http://dx.doi org/10.1016/j.leaqua.2009.10.005

Leroy, H., \& Sels, L. (2008). Authentic functioning: Being true to the Self in the organisation. Retrieved August 20, 2013, from https://lirias.kuleuven.be/ handle/123456789/198466

Lincoln, Y.S., \& Guba, E.G. (1985). Naturalistic inquiry. Newbury Park, CA: Sage Publications.

Luthans, F., \& Avolio, B.J. (2009). The 'point' of positive organizational behavior. Journa of Organizational Behaviour, 30, 291-307. http://dx.doi.org/10.1002/job.589

McLeod, J. (1999). Practitioner research in counselling. London: Sage Publications.

Meyer, T. (2007). The nature of leadership: Perspectives. In T. Meyer \& I. Boninelli (Eds.), Conversations in leadership: South African perspectives (pp. 3-17) Randburg, South Africa: Knowledge Resources.

Metcalf, L., \& Benn, S. (2013). Leadership for sustainability: An evolution of leadership ability. Journal of Business Ethics, 112, 369-384. http://dx.doi.org/10.1007/ s10551-012-1278-6

Peterson, S.J., Walumbwa, F.O., Avolio, B.J., \& Hannah, S.T. (2012). The relationship between authentic leadership and follower job performance: The mediating role of follower positivity in extreme contexts. The Leadership Quarterly, 23, 502-516. http://dx.doi.org/10.1016/j.leaqua.2011.12.004

Peus, C., Wesche, J.S., Streicher, B., Braun, S., \& Frey, D. (2012). Authentic leadership: An empirical test of its antecedents, consequences, and mediating mechanisms. Journal of Business Ethics, 107, 331-348. http://dx.doi.org/10.1007/s10551-011 $1042-3$
Rego, A., Sousa, F., Marques, C., \& Pina e Cunha, M. (2012). Hope and positive affect mediating the authentic leadership and creativity relationship. Journal of Busines Research, 67, 1-11. http://dx.doi.org/10.1016/j.jbusres.2012.10.003

Reichard, R.J., \& Avolio, B.J. (2005). Where are we? The status of leadership intervention research: A meta-analytic summary. In W.L. Gardner, B.J. Avolio, \& F.O. Walumbwa (Eds.) Monographs in leadership and management volume 3 : Authentic leadership theory and practice: Origins, effects and development, (pp. 203-226). Amsterdam: Elsevier.

Saldana, J. (2009). The coding manual for qualitative researchers. Los Angeles, CA: Sage.

Shamir, B., \& Eilam, G. (2005). 'What's your story?' A life stories approach to authentic leadership development. The Leadership Quarterly, 16(3), 395-417.

Teddlie, C., \& Tashakkori, A. (2004). Overview of contemporary issues in mixed method research. In A. Tashakkori \& C. Teddlie (Eds.), Mixed methods in social \& behavioral research. (2nd edn.). Los Angeles, CA: Sage.

Walumbwa, F.O., Avolio, B.J., Gardner, W.L., \& Peterson, S.J. (2008). Authentic leadership: Development and validation of a theory-based measure. Journal of Management, 34(1), 89-126. http://dx.doi.org/10.1177/0149206307308913

Walumbwa, F.O., Luthans, F., Avey, J.B., \& Oke, A. (2011). Authentically leading groups: The mediating role of collective psychological capital and trust. Journal of Organisational Behaviour, 32, 4-24. http://dx.doi.org/10.1002/job

Weischer, A.E., Weibler, J., \& Peterson, M. (2013). 'To thine own self be true':The effects of enactment and life storytelling on perceived leader authenticity. The Leadership Quarterly, 24, 477-495. http://dx.doi.org/10.1016/j.leaqua.2013.03.003

Wulffers, M.C.C. (2014). Evaluating a leadership authenticity programme. PhD thesis. University of Johannesburg, Johannesburg. 